\title{
ERRATUM
}

James R. Lovvorn · Samantha E. Richman

Jacqueline M. Grebmeier · Lee W. Cooper

\section{Diet and body condition of spectacled eiders wintering in pack ice of the Bering Sea}

\section{Polar Biology (2003) DOI 10.1007/s00300-003-0477-0}

The last paragraph of the section "Use of prey types, species and sizes" in the Discussion should be replaced by the following:

From the early 1960 s to the early 1980 s, dominance of benthic biomass in this area is thought to have shifted from $M$. calcarea to Nuculana radiata (Sirenko and Koltun 1992; National Research Council 1996). In March/April 2001, large samples from the dredge indicated that the biomass of M. calcarea was far lower than for Nuculana radiata (Fig. 3), and this difference appears to be the main reason that eiders ate mainly Nuculana radiata. Energy per gram dry mass (including shell) of the two clam species was about the same in the main length class eaten by eiders in the field. However, foraging studies with captive birds indicate that changes in length frequencies and burial depths have important effects on intake rates (S. E. Richman and J. R. Lovvorn, unpubl. data), and may have appreciably affected the profitability of diving $40-70 \mathrm{~m}$ to feed.

The online version of the original article can be found at http:// dx.doi.org/10.1007/s00300-003-0477-0

J.R. Lovvorn $(\bowtie) \cdot$ S.E. Richman

Department of Zoology, University of Wyoming, Laramie, WY 82071 USA

E-mail: lovvorn@uwyo.edu

Fax: +1-307-7666100

J.M. Grebmeier · L.W. Cooper

Department of Ecology and Evolutionary Biology, University of Tennessee, Knoxville, TN 37996 USA 